\title{
Di balik Branded Web Series kategori drama fiksi karya Yandy Laurens
}

\author{
Safina Zora Hassanah', Dian Wardiana Sjuchro ${ }^{2}$, dan Jimi Narotama Mahameruaji ${ }^{3}$ \\ 1,2,3 Universitas Padjadjaran, Bandung, Indonesia
}

\begin{abstract}
ABSTRAK
Penelitian ini berusaha mengungkap bagaimana strategi yang dimiliki oleh filmmaker dalam kapasitasnya mengolah cerita naskah branded web series kategori drama fiksi yang memilih beriklan pada media digital. Tujuan penelitian ini adalah untuk mengetahui alasan brand mau menggunakan konsep filmmaker dengan pendekatan soft-selling, memahami strategi filmmakers dalam menyampaikan pesan brand dengan cara softselling, serta memahami peluang branded web series pada masa yang akan datang. Metode yang digunakan adalah metode kualitatif, yaitu studi kasus eksplanatoris. Hasil penelitian ini menunjukkan bahwa sedari awal pihak brand menginginkan untuk tidak melakukan hard-selling pada serial web. Filmmakers dibukakan kebebasan sebesar mungkin dengan tetap mengemban tanggung jawab serta kedewasaan yang telah disepakati, yaitu mengutamakan visi dari market yang diinginkan. Penting bagi filmmakers untuk membuat sebuah ekosistem yang sehat dalam bekerja. Peluang branded web series di ranah digital dalam lima tahun kedepan diproyeksikan masih sangat cerah. Penelitian ini memberikan saran praktis kepada pihak-pihak lain yang menginginkan untuk membuat branded web series dengan pendekatan soft-selling layaknya karya dari Yandy Laurens berdasarkan dari hasil penelitian yang telah dilakukan ini. Tiap-tiap filmmakers agar dapat mendiskusikan dengan pihak brand ataupun agensi untuk dapat menemukan selling point dari tiap produk, mencatat hal-hal apa saja yang dapat mengungguli produk dari competitor lainnya, serta jelas menyasar market mana yang akan dituju. Selain itu, filmmakers diharapkan tidak menempatkan produk sebagai pahlawan yang menuntaskan semua permasalahan dari protagonis cerita. Produk harus diceritakan dengan natural dan tiap product placement yang ingin dibubuhkan agar diatur dalam rangkaian drama adegan sehingga masuk ke dalam cerita.
\end{abstract}

Kata-kata Kunci: Serial web, merek, menjual secara lunak, pemasaran, digital

\section{Behind Branded Web Series for fiction drama category by Yandy Laurens}

\begin{abstract}
This study seeks to uncover how the filmmaker's strategy in their capacity to process branded web series script stories that choose to advertise on digital media. The purpose of this research is to find out why brands want to use filmmakers with a soft-selling approach, understand filmmakers' strategies in conveying brand messages by soft-selling approach and estimate future branded web series opportunities. The method used is a qualitative method, which is an explanatory case study. The results of this study indicate that from the beginning the brand did not want to have a hard-selling approach on the web series project. Filmmakers are given as much freedom as possible while still carrying the agreed responsibilities and maturity, which prioritizes the vision of the desired market. Filmmakers need to create healthy ecosystems at work. Opportunities for the branded web series in the digital realm in the next five years are projected to be very bright. This research provides practical advice to other parties who want to create a branded web series with a soft-selling approach like the work of Yandy Laurens based on the results of this research. Each filmmakers can discuss with the brand or agency to find the selling point of each product, record what things can surpass the products of other competitors, and clearly target which market to go to. In addition, filmmakers are expected not to put the product as the hero that solves all the problems of the protagonist'story. The product must be told naturally and each product placement that you want to add is arranged in drama scenes series so it included in the story.
\end{abstract}

Keywords: Webseries; brand; soft-selling; marketing; digital

Korespondensi: Safina Zora Hassanah, S.I.Kom. Universitas Padjadjaran. Jl. Raya Bandung-Sumedang KM.21 Jatinangor. Email: safinazora@hotmail.com 


\section{PENDAHULUAN}

Toyota Indonesia meluncurkan serial web berjudul Mengakhiri Cinta Dalam 3 Episode yang kini telah menghasilkan lebih dari 5 juta views di kanal YouTube mereka. Tidak hanya Toyota, beberapa produsen serial web di Indonesia pun kini sengaja meramu cerita serial web mereka menjadi media promosi untuk brand lainnya. Berawal dari Maret 2015, Molto pernah melakukan hal tersebut melalui Impression of Your Fragrance.

Serial web merupakan sebuah medium penyampai cerita, dengan format yang sedikit diturunkan dari film sebagai akarnya. Film sendiri termasuk ke dalam industri ekonomi kreatif dan menurut data yang dihimpun Bekraf bersama BPS dalam Outlook Ekonomi Kreatif 2019, laju pertumbuhan PDB subsektor film, animasi dan video meningkat pesat seiring dengan meningkatnya produksi dan penonton film nasional. Sebesar 10,09\% dari laju pertumbuhan PDB pada indikator tersebut, tertinggi kedua di tahun 2016. Kenaikan yang signifikan pada periklanan via digital juga ditunjukan oleh Gambar 1.

Jika kualitas yang film miliki dapat diukur dengan perolehan rating melalui beberapa Indikator dari IMDb, Rotten Tomatoes, Meta Critics hingga Fandango, serial web belum memiliki sistem tersebut. Belum adanya barometer terhadap serial web mengharuskan penulis untuk membuat tolak ukur dari beberapa

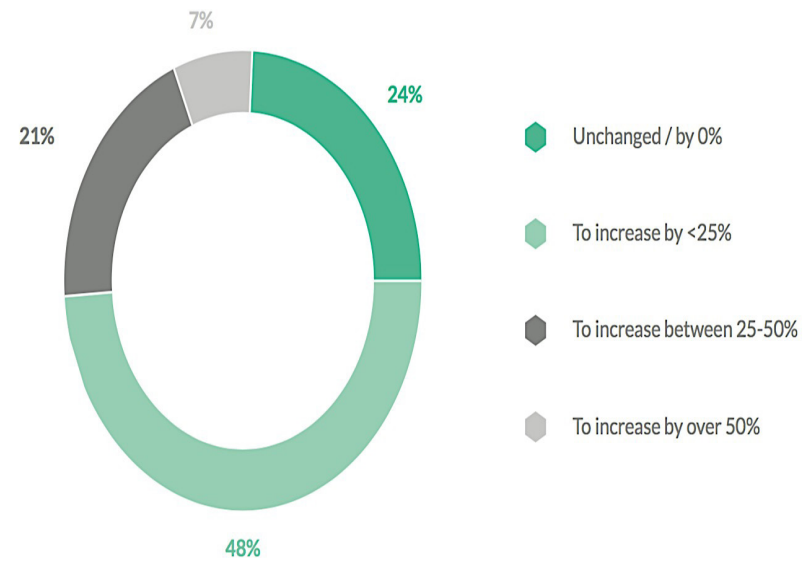

Sumber: Indonesia's Digital and Content Marketing Report, 2017

Gambar 1 Kenaikan digital marketing di Indonesia pada tahun 2017
Tabel 1 Barometer 12 Serial Web Indonesia dengan Penonton Episode Satu Terbanyak per April 2019

\begin{tabular}{|c|c|c|}
\hline No & Judul & Dilihat \\
\hline 1 & Surat Cinta Untuk Starla & 6.568 .465 \\
\hline 2 & Cinta di balik Awan & 5.355 .482 \\
\hline 3 & $\begin{array}{l}\text { Mengakhiri Cinta dalam } 3 \\
\text { Episode }\end{array}$ & 4.747 .315 \\
\hline 4 & $\begin{array}{l}\text { Bukti: Surat Cinta dari } \\
\text { Starla }\end{array}$ & 3.823 .809 \\
\hline 5. & [Kenapa Belum Nikah?] & 2.988 .636 \\
\hline 6. & $\begin{array}{l}\text { Axelerate The Series: } \\
\text { Kostan AX/3 }\end{array}$ & 2.957 .194 \\
\hline 7. & $\begin{array}{l}\text { Call Me Ai: The Story of the } \\
\text { Expert }\end{array}$ & 2.879 .228 \\
\hline 8. & Malam Minggu Miko & 2.854 .702 \\
\hline 9. & $\begin{array}{l}100 \text { days: Story of the } \\
\text { Expert }\end{array}$ & 2.653 .962 \\
\hline 10 & Love Distance & 2.649 .031 \\
\hline 11. & Sore: Istri dari Masa Depan & 2.406 .642 \\
\hline 12. & $\begin{array}{l}\text { Axelerate The Series: The } \\
\text { Untold Story }\end{array}$ & 2.220 .902 \\
\hline
\end{tabular}

Sumber: Olahan peneliti yang diakumulasikan dari 12 tautan Youtube, 2019

serial web Indonesia. Per April 2019, berikut merupakan beberapa serial web Indonesia pada platform YouTube dengan Indikator jumlah penonton episode pertama terbanyak yang ditampilkan pada tabel 1 .

Tabel 1 memperlihatkan perolehan jumlah penonton untuk serial web Mengakhiri Cinta dalam 3 Episode yang menempati urutan ketiga dari dua belas serial web lainnya. Untuk kategori branded web series, maka serial web tersebut menempati urutan pertama karena Surat Cinta Untuk Starla (2017) merupakan adaptasi dari sebuah lagu dari band Virgoun, sedangkan Cinta dibalik Awan (2016) merupakan kreasi independen tanpa bantuan sponsor.

Yandy Laurens selaku sutradara dari Mengakhiri Cinta dalam 3 Episode, biasa menulis sendiri naskah dalam setiap projeknya. Berlaku juga pada karya branded web series lainnya yaitu Sore: Istri dari Masa Depan (2017) dan juga Janji (2019)yang sama-sama disponsori oleh Tropicana Slim. Axe Indonesia 
juga sempat mensponsori branded web series miliknya berjudul Axelerate The Documentary (2017), namun serial web tersebut memiliki konsep dokumenter semi auto-biografi.

Perilaku beberapa brand yang secara eksklusif membuat sebuah cerita yang berpusat pada produk atau brand tersebut dikenal dengan istilah branded content, di mana hal tersebut dipercaya dapat memberikan pengalaman khusus serta membangun hubungan antara produk dan sasarannya (Dutta, 2019) Para produsen teks secara konsisten membuat, serta mengurasi konten-konten bernilai dan relevan dengan maksud mengubah atau memperbaiki perilaku konsumen.

Memasukan produk atau brand ke dalam sebuah program TV atau film akan memiliki keuntungan dari segi waktu dan perhatian. Ini menjadi kelebihan tersendiri dibandingkan beriklan secara spot. Penonton mempunyai peluang untuk menjadi captive audience di mana mereka seolah dipaksa melihat sebuah brand karena merupakan bagian dari isi cerita (Tampi \& Pamungkas, 2018).

Seluruh karya branded web series Yandy Laurens memiliki karakter soft-selling dalam menyampaikan pesan product-placement. Mengutip wawancara sang sutradara dengan Jurnal Ruang, seluruh karya dari Yandy memiliki karakteristik yang sama: ia mengemas secara penuh perasaan serta memori-memori personal di setiap karyanya (Rulianto, 2018). Hal ini yang mungkin kemudian memengaruhi kemampuannya dalam mengemas nilai-nilai sebuah brand dengan cara soft-selling pada karyanya.

Kini ribuan film bisa dipilih dan dinikmati melalui gawai. Maka tak heran jika setiap brand seperti berlomba-lomba dalam memproduksi konten dalam bentuk digital, seperti serial web yang mulai menjamur pada platform YouTube.

Budaya menonton televisi digital yang mengandalkan jaringan internet di Indonesia merupakan kegiatan personal dan individual, di mana audiens dapat memilih tontonan sesuai minat dan budget mereka. Penggunaan smartphone membuat kegiatan menonton televisi dapat dilakukan kapan pun dan di mana pun, dengan syarat tersedia jaringan internet yang memadai (Permana, dkk. 2019).

Setelah kenaikan yang terjadi pada periklanan melalui media digital cukup signifikan, fakta di lapangan masih menunjukan bahwa kue periklanan pada media konvensional televisi masih merajai pasar dalam negeri. Pada tahun 2018, informasi dari layanan sistem monitoring iklan televisi (TVC) adstensity mencatat bahwa brand masih mampu menghabiskan dana promosi sebesar Rp 110,46 triliun dalam belanja iklan. Angka tersebut ternyata memiliki pertumbuhan sebesar $13,35 \%$ dari periode tahun sebelumnya yang menghabiskan dana sebesar Rp 97,4 triliun. Hal tersebut membuktikan bahwa mayoritas brand masih lebih menghabiskan biaya beriklan pada media televisi dibanding dengan media digital yang dalam setahun masih menghabiskan biaya sekitar Rp 40 triliun (Tulus, 2019). Maka dari itu, penelitian ini berusaha mengungkap bagaimana strategi yang dimiliki oleh filmmaker dalam kapasitasnya mengolah cerita naskah branded web series.

\section{METODE PENELITIAN}

Metode yang digunakan adalah penelitian kualitatif studi kasus eksplanatoris dengan paradigma konstruktivisme. Agar dapat memahami bagaimana aktor sosial mencipta serta memelihara dunia sosial, paradigma ini memandang ilmu sosial sebagai analisis sistemis atas 'socially meaningful action' melalui pengamatan langsung tehadap aktor sosial dalam setting yang natural. Realitas itu ada, namun dalam bentuk konstruksi mental yang didasari pada pengalaman sosial, sifatnya lokal dan spesifik, dan bergantung pada siapa pihak yang melakukannya. Tidak seperti kalangan positivis dan post-positivistik, hasil yang didapat dari pengamatan terhadap realitas tidak dapat dilakukan generalisir terhadap semua orang.

Secara metodologis, aliran ini menerapkan metode hermeneutika dan dialektika dalam proses mencapai kebenaran. Metode pertama dilakukan melalui identifikasi kebenaran atau konstruksi pendapat orang per orang, sedangkan metode kedua mencoba untuk membandingkan 
dan dan menyilangkan pendapat orang per orang yang diperoleh dari metode pertama, untuk memperoleh suatu konsensus kebenaran yang disepakati bersama. Dengan demikian, hasil akhir dari suatu kebenaran merupakan perpaduan pendapat yang bersifat subjektif dan spesifik mengenai hal-hal tertentu (Salim, 2006).

Studi kasus eksplanatoris adalah jenis studi kasus yang digunakan untuk memberikan eksplanasi atau penjelasan dari stuatu persitiwa yang terjadi. Tujuan peneliti dalam studi kasus ini hendaknya untuk memajukan penjelasanpenjelasan tandingan untuk rangkaian peristiwa yang sama dan menunjukkan bagaimana penjelasan semacam itu mungkin diterapkan pada situasi yang lainnya. (Yin, 2011) Dari penjabaran tersebut maka studi kasus eksplanatoris merupakan metode yang tepat digunakan sebagaimana ia akan menjawab mengenai "bagaimana" porsi filmmaker ketika menentukan cerita dalam branded web series.

Dalam penelitian ini, objek penelitiannya adalah branded web series karya Yandy Laurens kategori drama fiksi. Terdapat tiga judul diantaranya Sore: Istri dari Masa Depan, Mengakhiri Cinta dalam 3 Episode, dan yang terakhir adalah Janji. Serial-serial web tersebut dipilih berdasarkan pertimbangan terhadap jumlah penonton episode satu terbanyak pada tabel hasil olahan peneliti dari 12 judul tautan Youtube per April 2019 yang lalu, menempatkan dua judul karya Yandy Laurens termasuk di dalamnya. Pemilihan kategori drama fiksi dilakukan untuk membatasi cakupan penelitian.

Subjek penelitian ini terdiri dari filmmaker serta produser dari branded web series, serta marketing communication pihak brand. (1) Yandy Laurens. Beliau merupakan filmmaker sekaligus dosen di IKJ. Bersama Hernu Rasyid dan Dimas Bagus mendirikan production house Cerita Films. (2) Hernu Rasyid, produser dari production house Cerita Films dan manajer dari Kunto Aji. (3) Ariel Christianto, seorang marketing communication associate manager sekaligus creative account manager dari PT Nutrifood. Dan (4) Arief Zakie, marketing communication Toyota Astra Motor dan juga sebagai supervisor di Digital Marketing.
Hal yang menjadi keunikan dari kasus yang diangkat dalam penelitian ini adalah banyaknya brand yang menaruh kepercayaan kepada Yandy Laurens untuk mengemas cerita terhadap pesan yang ingin mereka sampaikan dalam serial web.

Per April 2019, dari banyaknya serial web yang terdapat pada platform YouTube, kemunculan nama sutradara Yandy Laurens ditemukan sebanyak empat kali dibanding nama-nama sutradara lain yang maksimal terulang sebanyak dua kali. Tidak hanya itu, dalam branded content lain berbentuk film pendek, nama Yandy Laurens kembali muncul dalam brand Samsung, Aqua, juga KAO Indonesia.

Pengumpulan data dilakukan dengan menggunakan metode observasi, wawancara, studi pustaka, dan penelusuran data daring. Analisis data dilakukan dengan mengorganisasikan dan mengurutkan data ke dalam pola, kategori, dan satuan urutan dasar sehingga dapat ditemukan tema dan dapat dirumuskan hipotesis kerja seperti yang disarankan oleh data. Peneliti mencoba untuk menjaga prinsip dalam pengumpulan data studi kasus seperti yang diungkapkan oleh Yin mengikuti tiga prinsip, yaitu: Penggunaan Bukti Mutisumber, Menciptakan data dasar studi kasus, dan Memelihara rangkaian bukti (Mudzakir: 2014).

Pemeriksaan keabsahan data dilakukan untuk meningkatkan kemampuan peneliti dalam menilai keakuratan hasil penelitian, serta meyakinkan pembaca akan keakurasian penelitian. Dalam penelitian ini peneliti menggunakan metode Triangulasi. Menurut Bachri, triangulasi adalah suatu pendekatan analisa data yang mensistesa data dari berbagai sumber (Bachri: 2010). Selain melakukan triangulasi kepada para informan utama, penelitian ini juga menggunakan triangulator tambahan yang terdiri dari akademisi dan juga pengamat media. Melalui triangulasi, peneliti membandingkan data primer dan data sekunder yang diperoleh peneliti dari wawancara terhadap filmmaker dari serial web Mengakiri Cinta dalam 3 Episode. Setelah hasil wawancara didapat maka peneliti menyesuaikan dari informan dengan narasumber ahli. 


\section{HASIL DAN PEMBAHASAN}

Hasil penelitian dan pembahasan mengacu pada tujuan penelitian yang telah ditetapkan, yaitu untuk mengetahui alasan mengapa brand mau menggunakan konsep filmmaker dengan pendekatan soft-selling, strategi filmmakers dalam menyampaikan pesan brand dengan cara soft-selling, serta peluang branded web series pada masa yang akan datang. Pertama, alasan mengapa brand mau menggunakan konsep filmmaker dengan pendekatan soft-selling. Latar belakang dari serial web yang pertamaSore: Istri dari Masa Depan-merupakan hasil mengikuti festival yaitu Cinemadamare Film Festival 2016 di Itali. Setelah kembali ke Indonesia, terdapat pihak ketiga sebagai distributor yang tertarik untuk menjual karya tersebut kepada brand Tropicana untuk selanjutnya dijadikan branded web series yang ditayangkan pada kanal YouTube Tropicana Slim.

"Jadi ceritanya begitu Yandy udah pulang udah selesai di Itali, Yandy ketemu temennya. Terus temennya itu 'oh nih menarik banget nih buat salah satu brand, karena masuk isunya kesehatan' dan waktu itu emang produknya gaada brand sama sekali dan udah film gitu kan.. web series gitu. Akhirnya dijual, Tropicana Slim suka, mereka gak ada minta perubahan sama sekali, cuma.. yaudah deh masukin episode terakhir, ada brand Tropicana Slim-nya disitu.." (Wawancara dengan Hernu Rasyid, Produser Cerita Films pada 23 Juli 2019).

Namun hal berbeda dilakukan pada dua serial web lainnya. Setelah sukses dengan Sore, akhirnya Tropicana kembali mengajukan proposal untuk melanjutkan proyek serial web lainnya berjudul Janji. Sementara itu dua tahun sebelumnya, Toyota terlebih dahulu berinisiatif untuk membuat serial web Mengakhiri cinta dalam 3 Episode. Marketing Communication dari Toyota Astra bahkanmenegaskan bahwa pihaknya telah membuat riset untuk pembuatan serial web tersebut.

"Awalnya project ini berawal dari inisiatif kami. Sebelumnya sebelum melakukan project, kami selalu membuat research terlebih dahulu, apasih yang diinginkan millenials atau youth generations setara. Dan kami lihat youth-youth segment ini sudah tidak suka movie-movie yang sifatnya dua jam movie yang dragging-yang membosankan-mereka lebih suka yang short movie yang secara esensi langsung kena. Setelah itu baru kami nge-brief agensi, kami mau a,b,c,d" (Wawancara dengan Arief Zakie, Marketing Communication Toyota Astra pada 31 Juli 2019).

Jika mengamati ketiga serial web karya Yandy, semuanya memiliki pace bercerita yang agak lambat. Hal tersebut juga disadari oleh sang produser:

"Gak semua orang bisa nonton Sore loh! Karena Sore itukan treatment-nya.. Yandy itu pace-nya lambat sebenernya, kalo diliat ya.. di episode pertama, dia bisa intro aja bisa berapa menit sebelum masuk dialog. Terus, ya kaya gitu. Di Toyota pun kita ngerasa gak bisa semua orang nonton series itu" (Wawancara dengan Hernu Rasyid, Produser Cerita Films pada 23 Juli 2019).

Alasan mengapa brand memilih Yandy Laurens sebagai sutradara dari serial web kemudian dijawab oleh Marketing Communication Toyota Astra:

"Pertama kami berkaca dulu sama portofolio dari Yandy Laurens, dimana dia pernah membuat.. Tropicana ya? karena Tropicana itu unik, dari situ kita melihat the way he deliver the message itu sangat akurat, ya. Dia ngebungkusnya juga sangat baik, kalo pace itu discussable lah, bisa kita diskusikan" (Wawancara dengan Arief Zakie, Marketing Communication Toyota Astra pada 31 Juli 2019).

Sejak awal pihak brand sudah menginginkan proyek serial web ini diceritakan dalam balutan genre drama dengan tema besar cinta. Menurutnya, dua pilihan genre dari hasil suvei milik tim internalnya yang menunjukkan bahwa orang Indonesia menyukai genre horror dan romansa.

"Saya cuma bilang saya pingin buat minimovie yang secara tema love story, cuma tidak terlalu cheesy. Yang paling penting, kami adalah otomotiveindustry, bagaimana 
kalian men-deliver produk kamidengan baik dan se-soft mungkin" (Wawancara dengan Arief Zakie, Marketing Communication Toyota Astra pada 31 Juli 2019).

Namun, hasil riset tersebu juga menyatakan bahwa orang-orang pada segmen Yaris lebih menyukai pilihan genre romansa. Dan ketika ditanyakan mengenai seberapa besar intensitas untuk menampilkan produk dalam serial web tersebut, rupanya pihak dari brand sejak awal sudah memberi arahan: 'di dalam brief kita tekankan, kita gak boleh hardselling.' Hal tersebut memang sudah sangat sejalan dengan visi sang sutradara. Pernyataan tersebut mematahkan anggapan peneliti bahwa yang production house lah yang sejak awal mengonsep branded web series Mengakhiri Cinta dalam 3 Episode menampilkan produk dari brand secara soft-selling.

Kedua, strategi filmmakers dalam menyampaikan pesan brand dengan cara softselling. Proses kreatif yang terjadi dibalik pengerjaan karya-karya serial web milik Cerita Films biasanya dimulai dengan permintaan dari sisi production house kepada pihak brand maupun agensi untuk memberikan kepercayaan penuh terhadap sutradara. Sehingga sang sutradara memiliki ruang gerak yang lebih dalam mengerjakan setiap karyanya. Hal tersebut diungkap Yandy ketika ditanyakan tentang apakah proses kreatif sepenuhnya diserahkan kepada pihaknya.

"(sepenuhnya kepada) Production house dengan membuka ruang diskusi juga dengan pihak agensi dan brand. Tapi sifatnya trust ke production house. Tentu ini trust nya mutual sih, ya mereka percaya sama kita lakukan kreatif terbaik, kita percaya sama mereka juga agar arahan-arahan atau halhal yang sifatnya fundamental seperti product placement itu yang kita sepakati" (Wawancara dengan Yandy Laurens, sutradara Cerita Films pada 26 Juli 2019).

Karena kepercayaan penuh yang dimiliki oleh pihak production house, peneliti mempertanyakan bagaimana proses diskusi brief yang berlangsung diantara pihak production house dengan agensi yang terlibat, seperti apa perbedaan dari jobdesc masing-masing pihak terhadap proyek yang sedang dikerjakan. Yandy Laurens kemudian memaparkannya dengan memberikan contoh tentang proyek bersama Tropicana yang biasanya tidak menggunakan bantuan pihak agensi.

"Tropicana slim, sisi kreatif dipercayakan ke kita tapi kalo ada agensi.. kita lah yang meminta untuk sistemnya mempercayakan ke kita. Tentu kita membaca apakah kebutuhan promonya, apa yang ingin dicapai, apa tergetnya, apa yang mau dijual. Lalu kita minta kepercayaan penuh kepada Cerita Films untuk membuat Ceritanya" (Wawancara dengan Yandy Laurens, sutradara Cerita Films pada 26 Juli 2019).

Dalam kasus serial-serial web karya Yandy Laurens, Cerita Films memiliki konsep bank story, dimana terdapat kumpulan cerita berbentuk sinopsis panjang yang nantinya kemudian dipilih kepada klien mana ceritacerita tersebut paling tepat untuk diproduksi lebih lanjut.

Ada beberapa pertimbangan yang dibuat dalam menentukan cerita mana yang akan dipakai dalam sebuah proyek. Biasanya premis awal pada tiap proyek ditulis oleh Yandy Laurens yang merangkap sutradara sekaligus penulis naskah. Kemudian produser juga ikut dalam pengembangan cerita lebih lanjut.

"Semuanya saya tulis sendiri sih.. benerbener written by Yandy Laurens. Produser dan agensi dan klien tuh punya ruang untuk memberi feedback, tapi seperti di perjanjian awal.. selama itu sisi kreatif dari awal kita sepakat bahwa itu dipercayakan ke saya kecuali beberapa hal sifatnya langsung ke image brand itu pasti kami sangat pertimbangkan. Tapi kalo sifatnya pertimbangan kreatif, biasanya agensi dan kliennya sudah percaya sama Cerita Films" (Wawancara dengan Yandy Laurens, sutradara Cerita Films pada 26 Juli 2019).

Yandy Laurens kemudian menjelaskan lebih lanjut tentang proses menulis yang harus ia lalui setelah memilih sebuah sinopsis untuk dikembangkan menjadi naskah. Ia mengaku peristiwa dalam hidupnya telah banyak memengaruhi dirinya dalam membuat cerita, 
bukan tokoh tertentu ataupun orang terdekat.

"Menulis itu cepat, merangkai makna, kedalaman karakter itu yang lama, saya banyak berbicara dengan orang-orang, mengumpulkan pandangan berbagai teman tentang pandangan saya tentang cerita itu. Kumpulan itu jadi bahan perenungan. Biasanya saya lah orang pertama yang beruntung mendapatkan pesan atau pemaknaan hidup itu terlebih dahulu, selebihnya, tinggal kegiatan menuangnya dalam naratif menggunakan teori-teori penulisan yang bisa diakses dimana saja itu" (Wawancara dengan Yandy Laurens, sutradara Cerita Films pada 26 Juli 2019).

Di akhir 2017, Yandy mengaku pada wawancara yang dilaksanakan oleh Jurnal Ruang di kantor Visinema Pictures mengenai pentingnya membubuhkan pengalaman personalnya dalam setiap cerita yang ia buat.

"Kadang dapat cerita seaneh apa pun kalau core ceritanya enggak bisa ditarik ke apa yang pernah saya rasakan, saya merasa bercerita ke orang tapi bohong. Jadi selalu bisa menaruh pandangan insight tentang hidup ke dalam cerita itu penting" (Yandy Laurens dalam wawancara oleh Jurnal Ruang tanggal 9 Maret 2018).

Sang produser menjelaskan ketika pihaknya mengambil sebuah proyek untuk dikerjakan, maka mereka akan memberikan atensi sepenuhnya terhadap proyek tersebut. Persiapan yang dilakukan terhadap sebuah proyek bisa memakan waktu hingga satu tahun lamanya.

"Karena kita sadar, kita gak bisa tuh.. Safina.. kaya terima brief brand yang 'nih ada brief, budget-nya sekian tapi develop, eh deliver-nya bulan depan.. atau dua bulan..' kita gak bisa. Karena kita sadar, karya yang bagus emang harus di treatment secara proper, jadi kita kaya.. Toyota itu pre-production-nya bisa sampai-mulai dari syuting - tiga sampai empat bulan gitu. Post-production lima bulan. Kalo Janji ini bahkan kita udah ketemu dari.. sama brand nya dari pertengahan tahun lalu udah ngobrolin budget segala macem gitu-gitu. Karena persiapannya emang harus proper banget. Reading yang panjang, scouting lokasi yang pas segala macemnya gitugitu" (Yandy Laurens dalam wawancara oleh Jurnal Ruang tanggal 9 Maret 2018).

Hal tersebut adalah salah satu alasan yang mendasari dibuatnya Cerita Films sebagai production house yang berdiri sendiri, setelah sebelumnya Yandy dan Hernu dipertemukan pada project film Tabula Rasa.

"Karena kita ngerasa, kita pengen punya ekosistem yang sehat dalam bekerja bikin karya gitu, karena kalo Yandy bilang sih, 'bikin film itu tergantung sama siapanya, bukan seberapa besar budget' bukan apa segala macem, tapi tergantung kita bikin sama siapa. Kalo nyaman sama ekosistemnya, pasti akan sangat memengaruhi karyanya, gitu" (Yandy Laurens dalam wawancara oleh Jurnal Ruang tanggal 9 Maret 2018).

Sang produser menjelaskan, produk yang masuk dalam branded web series yang digarap oleh Cerita Films tidak dapat diperlihatkan sebagai jalan keluar dari masalah yang dihadapi oleh protagonis. Yang diutamakan tetaplah alur cerita dari sinopsis yang telah disepakati sebelumnya.

"Ketika brand mau soft-selling masuk ke konten yang ditonton banyak orang, produk tidak bisa menjadi hero, jadi yang didahuluin adalah ceritanya. Produk masuk dengan ya... bentuk komunikasi cukup disitu gitu. Tapi yang menentukan adalah ceritanya. Jadi kita selalu komunikasinya adalah percayain semua ke kita 100\%" (Wawancara dengan Hernu Rasyid, Produser Cerita Films pada 23 Juli 2019).

Sebelum memulai sebuah proyek, kedua belah pihak diminta untuk sama-sama membagikan value atau nilai-nilai yang dipegang masing-masing. Misalnya, nilai yang ingin ditanamkan oleh pihak Tropicana Slim adalah narasi hidup sehat, atau secara kata perkata Marketing Communication Nutrifood menjelaskan: "Menginspirasi generasi muda untuk mulai hidup sehat, dan menanamkan persepsi bahwa hidup sehat bisa dijalankan dengan menyenangkan."

Peneliti berusaha mengonfirmasi mengenai 
kemungkinan adanya pertentangan yang terjadi diantara pihak brand dan production house. Pertanyaan itu diberikan kepada masing-masing dari marketing communication tiap brand. Pihak Tropicana Slim memberikan pernyataan bahwa semua kepentingan telah disampaikan, difasilitasi, dan disepakati. Sejalan dengan itu, pihak Toyota menceritakan impresi mereka terhadap Yandy Laurens: "Nah ini yang saya suka dari Mas Yandy, Mas Yandy selalu mengakomodir semua needs kami”, ungkap Arief Zakie.

Sehingga dapat dipastikan bahwa tidak ada pertentangan yang terjadi diantara mereka. Dari titik saling membagikan nilai yang dipegang, berlanjut kepada tahap tawar menawar yang sutradara sebut sebagai tahapan bargaining. Dan jika nilai yang dipegang sangat bertentangan secara fundamental, maka Yandy lebih memilih untuk menolak proyek tersebut.

"Jawaban saya pasti daripada nanti tidak jadi seperti yang teman-teman inginkan, karena biasanya teman-teman itu datang dengan ekspektasi 'mau kaya Sore, mau kaya Toyota' dan untuk mencapai itu kan dibutuhkan ekosistem yang selama ini kita jalankan. Nah kalo itu dilanggar atau itu dikekang atau itu dikurangi, saya malah curiga dan takut sekali nanti hasilnya tidak sesuai ekspektasi, malah merugikan yang datang minta itu. Sebenernya untuk kebaikan semua pihak sih. Jadi kalo pertanyaannya apakah permintaan dari brand bertentangan dengan nilai yang saya pegang.. ya jawabanya tidak ada, karena kalo ada project-nya gak jalan dari awal" (Wawancara dengan Yandy Laurens, sutradara Cerita Films pada 26 Juli 2019).

Ketiga, peluang branded web series pada masa yang akan datang. Peneliti menanyakan peluang bagi branded web series yang biasa ditampilkan pada platform YouTube kedepannya. Yandy Laurens pun melihat adanya transisi dari beberapa brand untuk membelanjakan anggaran marketing-nya pada ranah digital lebih besar dari periode sebelumnya.

"Menarik pertanyaannya, karena memang kue nya lagi transisi kok. Jadi ada migrasi perlahan. Jadi kita lagi ada di pasar transisi di mana pengiklan yang dulu rame di
TVC sekarang lagi migrasi rame-rame ke digital ke YouTube karena beberapa produk sasarannya atau market-nya tidak nonton TV lagi kan, tapi nonton YouTube. Jadi secara budget ya juga, ya perlahan naik. Masa depan cerah untuk web series, mungkin tiga atau lima tahun ke depan dia akan naik. 'Kok sampe lima tahun aja?' karena saya belum bisa tebak lima tahun ke depan ada perubahan apa lagi tapi kayanya lima tahun kedepan pun web series masih menarik. Harusnya ya. Kira-kira begitu" (Wawancara dengan Yandy Laurens, sutradara Cerita Films pada 26 Juli 2019).

Di dalam dunia ini tidak ada sebuah produk atau sebuah perusahaan yang bisa menyenangkan semua orang, karena pada dasarnya setiap orang memiliki kebutuhan yang berbeda. Mereka pasti memiliki preferensi yang berbeda terhadap produk gula atau mobil yang ingin mereka gunakan. Maka Toyota dan juga Tropicana Slim harus melakukan apa yang biasa dalam dunia marketing disebut dengan istilah STP (Segmenting, Targeting, Positioning). Bagi Toyota, proses awal dari serial web ini pun berangkat dari sisi pemasaran, di mana fokus bergerak dari STP.

"Jadi pada saat kami nge-brief atau saat meng-initiate project ini, yang pertama harus kita lihat as a marketer, kita bergerak dari STP ya. Segmentasi, targeting dan positioning. Nah secara produk kita lihat Yaris ini secara STP cocok untuk dibuatkan miniseries. Dan setelah itu kami decide untuk menemui agensi kami, Densu. Nah Densu merekomendasikan kami Yandy Laurens, in-line dengan kemauan kami. Dan setelah itu, berjalan seperti itu“ (Wawancara dengan Arief Zakie, Marketing Communication Toyota Astra pada 31 Juli 2019).

Menurut seorang deputy CEO dari MarkPlus.Inc Iwan Setiawan, Segmentasi digunakan supaya kita tahu dari sekian banyak orang yang ada di sebuah pasar, mana saja dari orang-orang tersebut yang ingin suatu perusahaan targetkan.

"Kalau kita sudah membagi-bagi pasar menjadi segmen-segmen yang menurut 
kita berpotensi untuk membeli produk kita, tugas kita berikutnya adalah memilih segmen mana yang kira-kira ingin kita layani. Inilah targeting. Segmentation dan targeting selalu beriringan" (Wawancara dengan Iwan Setiawan, CEO MarkPlus.Inc pada Juli 2019).

Setelah mengetahui segmentasi dari produk dan target pasar mana yang dituju oleh Toyota, mereka kemudian menggunakan brand ambassador untuk bisa mengaitkan sebuah citra yang dituju pada segmentasi Yaris.

"For the sake of awareness ya kalo saya liat, jadi, brand ambassador sangat esensial di produk-produk tertentu, apalagi produk-produk yang membutuhkan boosting image, seperti.. Yaris gitu ya. Yaris kan secara segmentasi Yaris itu harus terlihat muda, youthful, cheerful, dan disitu kami membutuhkan seorang sosok yang bisa nge-boost dari image-image yang kami butuhkan" (Wawancara dengan Arief Zakie, Marketing Communication Toyota Astra pada 31 Juli 2019).

Dalam ranah digital marketing terdapat istilah KPI(Key Performance Indicator), dan pihak Toyota Astra sempat memberitahukan sebagian dari KPI yang mereka gunakan untuk menghitung pencapaian dari serial web Mengakhiri Cinta dalam 3 Episode pada bagian hasil penelitian sebelumnya. Sebagian kecil KPI mereka antara lain engagement dalam artian berapa positive dan negative feedback yang mereka dapatkan di video tersebut serta demografik dari penonton serial web. Peneliti menanyakan tentang tingkat efektivitas yang tergambar dalam metrik yang digunakan. Peneliti menanyakannya kepada beberapa triangulator penelitian, yang salah satunya adalah Sofyana Ali Bindiar yang merupakan triangulator dari sisi pengamat media. Beliau menjelaskan bahwa branded web series hanya merupakan salah satu cara mengomunikasikan pesan.

"Kan gini, ngomongin brand series itu ngomongin channel komunikasi. Bukan ngomongin soal bahwa ini adalah satu karya film gitu, atau apapun lah yang berhubungan. Jadi memang lebih luas, gitu. Dan ini adalah tools iklan gitu kan. Brand series ini tuh fungsi iklan. Dan iklan itu, gitu ya, kalo misalnya dia ngomongin $K P I$ nya sangat luntur gitu ya, misalnya brand ini dia ngeset KPI-nya engagement brand ini misalnya $K P I$-nya itu misalnya viewers. Film mereka, mereka sudah punya set posisition-nya. Set position-nya itu dibangun misalkan dalam satu campaign gitu ya, kalo misalnya bicara campaign kan itu ada AIDA,awareness, gitu kan, interest, gitu ya, terus sampe berakhir di action. Dia mau ngejar kemana? Gitu kan" (Wawancara dengan Sofyana Ali Bindiar, pendiri Bandung Film Comission pada Rabu, 7 Agustus 2019).

Selaras dengan apa yang diungkapkan Sofyana Ali, Abdalah Gifar Abisena yang juga merupakan kolega dari Sofyana di Bandung Film Comission menyatakan pendapatnya. Baginya, brand Toyota tidaklah terlalu muluk dalam menetapkan target karena yang disasar merupakan tahapan pertama dari purchasing funnel, yaitu step awareness yang terdapat dalam teori marketing yang sempat disebutkan oleh Sofyana Ali pada penjabaran di atas: AIDA.

Model ini membentuk hierarki linier, pertama kali dikembangkan pada tahun 1989 oleh St. Elmo Lewis. Agar termotivasi untuk melakukan pembelian (action), pelanggan harus dikonversikan dari sadar (aware) akan keberadaan produk, menjadi cukup tertarik (interest) terhadap keunggulan produk, hingga memiliki keinginan (desire) untuk mendapatkan

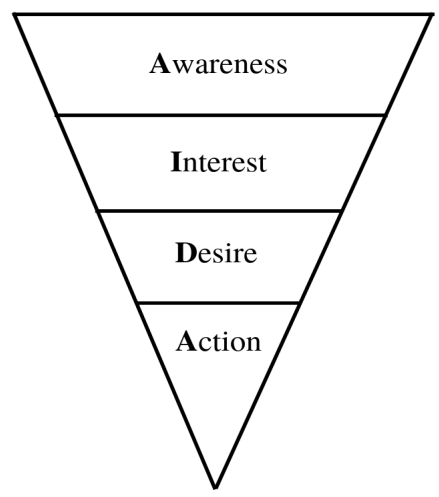

Sumber: Ryte Wiki, 2019

Gambar 2 Model AIDA (Awareness, Interest, Desire, Action) 
manfaat produk. Meskipun diambil dari upaya Lewis dalam mengetahui bagaimana personal selling bekerja, banyak ahli teori pemasaran dan periklanan yang selama setengah abad berikutnya menggunakan model yang sama (Doyle, 2011).

Walaupun masih sering dipergunakan, model tersebut dianggap terlalu tua bagi sebagian kalangan pemasar. Menurut Hermawan Kertajaya (dalam Tampi, \& Pamungkas, 2018), para marketing communication kini banyak beralih dengan model customer path, yang merupakan salah satu instrumen yang tepat untuk memasarkan produk atau jasa. Tiap jenis industri memiliki perbedaan customer path. Dengan adanya era konektivitas seperti sekarang ini, customer path telah berevolusi dari yang sebelumnya dikenal dengan sebutan 4A: Aware, Attitude, Act, Act again; menjadi 5A: Aware, Appeal, Ask, Act, dan Advocate. Pada model 4A, konsumen dianggap akan kembali melakukan pembelian jika sebelumnya aksi pembelian tersebut pernah dilakukan. Namun dalam era konektivitas yang terjadi saat ini, barometer keberhasilan pemasaran tidak berasal dari pembelian berulang. Karena faktanya tidak semua industri dapat membuat konsumennya untuk melakukan pembelian secara berkala dalam periode waktu singkat, seperti keputusan untuk membeli mobil Toyota Yaris, misalnya.

Untuk dapat mengonversi dari tahap awareness menuju tahap action membutuhkan usaha lebih dalam mengintegrasikan kegiatan marketing. Dalam industrinya, Gifar Abisena menceritakan tentang masih banyaknya calon klien yang langsung meminta output berupa sales ketika diminta dibuatkan campaign komunikasi.

"Tapi justru sebenaranya visi yang lebih luas lagi sebenarnya, banyak perusahaan atau brand pengen yang lebih kongkrit, gitu. Maksudya kongkrit tuh maunya mereka output-nya langsung sales. Langsung selling. Setidaknya, konten-konten ataupun bentuk komunikasi yang coba dia bikin itu punya banyak.. terpapar ke banyak orang. Tanda views tuh menjadi satu... salah satu bentuk penentuan KPI kuantitatif dibanding sebatas awareness, dibanding sebatas bahwa oh ini feedback-nya positif atau negatif" (Wawancara dengan Abdalah Gifar Abisena, pendiri Bandung Film Comission Rabu, 7 Agustus 2019).

Pendapat lain mengenai tingkat efektivitas penggunaan metrik yang diungkapkan oleh Toyota diutarakan oleh Bapak Detta Rahmawan, S.I.Kom, MA. selaku dosen di Fakultas Ilmu Komunikasi dengan background riset yang berkaitan dengan bisnis dan industri media digital. Beliau menjelaskan:

"Ya kalo misalnya di dalam dunia bisnis itu kan yang namanya KPI kan biasanya ditentukan oleh pemberi pekerjaan kan? Dalam hal ini brand gitu. Cuma kan dalam kaitannya nanti si brand itu sebetulnya gak akan langsung ke platform-Youtubekan misalnya. Jadi brand tuh harus lewat dulu agensi, agensi harus nyari ke content producer, content producer nanti harus ke publisher ya namanya yang dimana, publisher nya ini nanti dia langsung di

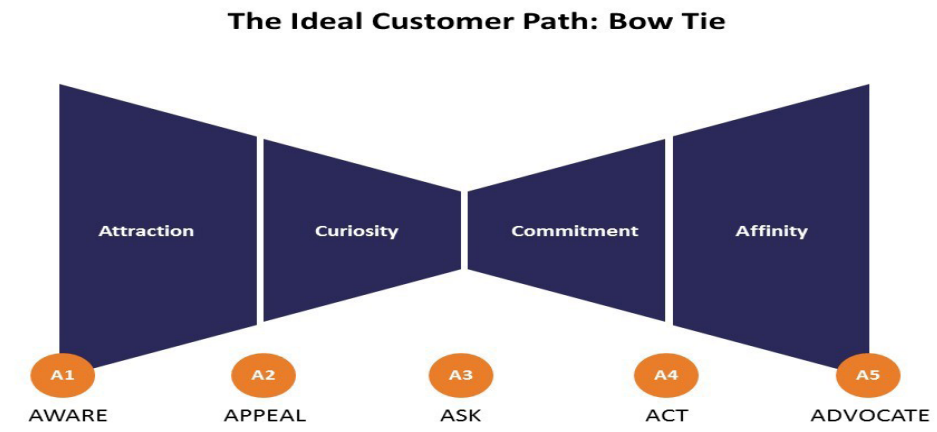

Sumber: Binus, 2017

Gambar 3 Ideal Customer Path 5A: Bow Tie Model

Di balik Branded Web Series kategori drama fiksi karya Yandy Laurens 
bypass ke platform kalo dulu kan media. Nah si KPI itu sebetulnya juga akan.. hm kita bisa melihat dari dua jenis sih. Yang satu kita bisa ngeliat dari day to day activities gitu jadi.. oh yang tadi kamu sebutkan itu metrik yang punya Toyota? Kalo misalnya sebagai brand tuh dia menganggap berhasil dengan metrik yang dia punya ya berarti tuh, yaudah pendapat mereka itu that's fine ya oke oke aja" (Wawancara dengan Detta Rahmawan, dosen Fikom Unpad pada tanggal Rabu, 7 Agustus 2019).

Dari paparan pendapat tersebut, peneliti memiliki asumsi bahwa dengan bebasnya kadar menentukan keberhasilan suatu campaign maka cara aman dalam membuat suatu campaign berhasil adalah dengan meminimalkan capaian target dari KPI. Di sisi lain, Sofyana Ali Bindiar kembali menegaskan bahwa seharusnya brand tidak menetapkan capaian KPI yang rendah.

"Maksudnya dia (brand) juga mempertaruhkan banyak hal lah kalo gitu. Misalnya untuk seperti itu apalagi ya kalau kita ngomongin web series itu brand series gitu ya memang iklan kan harusnya kan kalo beberapa dari kalangan temen-temen pun bilang bahwa advertising is sells. Jadi semua yang masuk iklan itu harus bisa dijual. Nah channel jualan Toyota kan nggak cuma channel komunikasi jualan dia kan kalau ngomongin komunikasi pemasaran enggak cuma soal brand series, gitu. channel komunikasi dia tuh banyak banget. Tapi salah satunya, untuk nangkep awareness-nya, dia melalui brand series. Tapi turunan komunikasi pemasaran dia yang lain itu ada lain yang punya levellevel yang lain, yang setting level KPI yang lain hingga ke action. Action itu biasanya dia diaktivasi dari activation. Gitu sih" (Wawancara dengan Sofyana Ali Bindiar, pendiri Bandung Film Comission pada Rabu, 7 Agustus 2019).

Turunan dari komunikasi pemasaran yang diungkapkan oleh Sofyana Ali Bindiar berkaitan dengan integrasi antara ATL (Above the Line) dan BTL (Below The Line). Penjelasan mudah mengenai ATL dan BTL disampaikan dalam sebuah video interaktif mengenai brand dalam kursus Indonesia X mengenai Pemasaran Efektif di Era Digital. Penjelasannya antara lain:

"Kalau misalnya ATL itu adalah media yang digunakan yang objektifnya untuk exposure. Dia akan mencakup audiens yang lebih luas. Audiens itu tahu kalau ini iklan, itu adalah ATL. Orang itu misalnya kalau melihat iklan TV, ini ada iklan, misalnya, itu disebut ATL. Radio, misalnya, diiklankan satu merek properti yang sangat booming sekali: belilah, belilah itu disebutnya ATL: Above the Line. Customer merasa dijualkan oleh perusahaannya, oleh sebuah brand, disebutnya maka itu Above the Line. Above the Line itu bisa radio, bisa televisi, bisa billboard, bisa apapun, yang sifatnya exposure satu arah ke customer tanpa ada engagement atau interaksi lebih lanjut. Itu ATL. BTL, di sisi yang lain adalah sebuah aktivasi yang tujuannya adalah membantu brand itu berinteraksi lebih jauh dengan customer-nya. Ada engagement disana, Below the Line. Contohnya banyak sekali: ada event, ada roadshow, ada workshop, kuis, kompetisi, yang dimana customernya terlibat di dalamnya. Kita sebut Below the Line" (Savitry, 2019).

Dan hal-hal tersebut telah dilakukan oleh Toyota dalam serangkaian promosi event yang sejalan dengan branded web series mereka. Toyota telah menyelenggarakan serangkaian promosi BTL dijelaskan oleh marketing communication dari Toyota Astra:

"Safety campaign, iya itu memang salah satu strategi kami. Jadi yang harus diliat juga bagaimana Yaris ini mempunyai spec safety yang sangatlah lengkap dibanding denan kompetitornya. Dan kami tidak hanya ingin menjual mobil ke customer, tapi kami juga ingin mengedukasi si customer. Mengedukasi customer bahwa mobil tidak melalui tentang kencangkencangan, ngebut-ngebutan, ada safety aspect juga yang harus tetep dipikirkan. Makanya kita tetep jalan campus to campus. Kemarin kan kita fokusin di Jawa, cuma tahun ini kita fokusin di Sumatera. Nanti saya yang akan jadi speaker di Sumatera" (Wawancara dengan AriefZakie, Marketing Communication Toyota Astra pada tanggal 31 Juli 2019). 
Selain seminar antar kampus di Jawa dan Sumatera mengenai pentingnya keselamatan dalam berkendara, Toyota juga berusaha menonjolkan citra sporty dari Yaris dengan tiga kali berpartisipasi dalam lomba touring sampai ke tahapan kejuaraan nasional. Bahkan, Aief mengaku bahwa Toyota Yaris telah memenangkan tiga kali kejuaraan nasional tersebut. Sementara itu, hal yang dilakukan Toyota dalam promosi Above the Line tentunya banyak fokus dengan iklan dengan media televisi. Dalam hasil penelitian di atas, peneliti telah mewawancarai pendapat-pendapat dari para narasumber kunci mengenai porsi kue iklan televisi yang masih jauh di atas jumlah iklan digital meskipun dari tahun ke tahun pertumbuhan iklan digital masih berada di tren yang positif. Berikut ini merupakan pendapat dari para triangulator mengenai fenomena tersebut:

"Saya pikir sekarang trennya masih besar karena memang biaya atau anggaran iklan tv masih tinggi, bisa dibilang kalau dikomparasikan dengan misalkan digital ads gitu ya. Ataupun dengan bentukan iklan di website ataupun di internet lah ya, apapun kontennya. Jadi memang ini masih jadi bisa dibilang masa leganya bagi para pemilik stasiun televisi" (Wawancara dengan Abdalah Gifar Abisena, pendiri Bandung Film Comission Rabu, 7 Agustus 2019).

Namun pernyataan skepstis diutarakan oleh Bapak Detta Rahmawan, sebagai triangulator di bidang akademisi. Ia berpendapat bahwa mengonversikan tahap awareness menuju tahap action akan sulit dilakukan untuk produk Toyota. Sehingga ia setuju jika sasaran KPI dari Toyota hanya sampai di tahap awareness.

"Web series gitu ya mungkin saya melihatnya masih akan sangat kepada tujuan untuk membentuk percakapan, buzz, image. Buat saya sih masih sangat susah untuk kemudian langsung converts ke sales gitu ya apalagi Toyota. Maksudnya berapa banyak sih orang yang nonton iklan Toyota terus pengen beli mobil? Kan gitu pertanyaannya?" (Wawancara dengan Detta Rahmawan, dosen Fikom Unpad pada tanggal Rabu, 7 Agustus 2019).
Bagi Gifar Abisena, bisnis pertelevisian relatif masih aman di Indonesia dikarenakan secara anggaran, nilai atau penyebaran masih kuat. Daya jangkaunya yang luas dan cepat untuk masuk dibandingkan dengan penetrasi internet di daerah menjadi alasannya. Peneliti menanyakan kemungkinan suatu saat kue televisi tersalib dengan anggaran digital. Ia memberikan konfirmasi atas membesarnya anggaran digital dari brand yang ia pegang, namun membantah jika pesona yang ditawarkan televisi maupun media-media above the line akan pudar.

"Kalau misalnya berbicara tentang kue atau pembagian anggaran, saya menyadari karena memang salah satu pekerjaan saya di kantor saya adalah memang menyarankan ke branded tertentu. Dan mereka secara anggaran mulai membesarkan anggaran belanja iklan digital. Ada memang anggaran belanja luar ruang Billboard gitu above the line. Jadi kalau di televisi itu nggak mungkin langsung akan hilang tapi memang untuk digital Apakah porsinya dari mana dia ambil itu setiap perusahaan memiliki kebijakan yang berbeda. Tapi bisa kayak di Billboard akan tetep ada produk mempertahankan billboard karena sudah punya kualitas tersendiri. Ada juga yang dia mengeluarkannya di internet Jadi saya pikir. Kuenya besar di mana pun saya amatin setelah berinteraksi dan juga berinteraksi dengan beberapa brand yang saya coba servis secara bentuk kontennya, jadi memang sudah mulai anggaran untuk digital itu dibesarkan" (Wawancara dengan Abdalah Gifar Abisena, pendiri Bandung Film Comission Rabu, 7 Agustus 2019).

Jika khusus membicarakan tentang branded web series, ia mengutip pernyataan dari pakar komunikasi UI-Dr. Hifni Alifahmi-yang menyebutkan bahwa ke depan salah satu komunikasi pemasaran akan banyak berbentuk narrative marketing.

"Narrative marketing ini jadi memang akan membuat sebuah produk tuh dipasarkan menjadi sebuah penceritaan. Ada faktor cerita di balik pemasaran produk. Karena orang tidak lagi bicara fungsional terhadap 
produk tapi sisi emosional. Apa sih sisi emosional sebuah produk sehingga itu relatif maupun cocok dengan konsumen. Bukan lagi mobil bahwa sama-sama mobil bahwa produk makanan saja ya sama-sama aja hanya varian yang berbeda-beda tapi pada ujungnya yang paling relate, mana sih yang paling memang punya sisi di luar fungsional. Itulah memang harus naratif ini yang kuat" (Wawancara dengan Abdalah Gifar Abisena, pendiri Bandung Film Comission Rabu, 7 Agustus 2019).

Sejalan dengan pernyataan di atas, Sofyana Ali Bindiar menambahkan bahwa kini produkproduk mulai detail menyasar target-target audiens tertentu. Perusahaan mulai berusaha menyampaikan pesannya dengan lebih intim, layaknya berkomunikasi dengan teman dekat yang akan lebih mudah dipercayai ketimbang dengan orang yang tidak dikenal. Ia juga menekankan bahwa proses storytelling kian waktu makin dikembangkan agar lebih personal.

"Tadi kalo ngomongin Gifar bilang soal emosi. Nah betul kenapa sekarang storytelling itu digunakan oleh brand atau storytelling digunakan oleh produk itu untuk menjajakan produknya? Produk Enggak lagi ngomongin soal mass communication mengharap target audience itu sama. Mereka lebih spesifik lebih detail sehingga komunikasi-komunikasi yang diangkat itu komunikasi-komunikasi yang intimate" (Wawancara dengan Sofyana Ali Bindiar, pendiri Bandung Film Comission pada Rabu, 7 Agustus 2019).

Menurut peneliti, proses narrative marketing yang dibicarakan di atas dapat disamakan dengan konsep Entertainment Branding yang diangkat dalam penelitian Tampi \& Pamungkas (2018). Menurut mereka, Entertainment branding dilakukan dengan objektif untuk menyatukan dunia hiburanterutama film-dengan dunia periklanan. Dalam metodenya, pesan dari pihak brand akan diintegrasikan dengan konteks yang tepat sebagai bagian dari interaksi. Walaupun terbilang baru, sudah banyak perusahaan yang mencoba metode tersebut. Salah satu contohnya adalah keterlibatan para sponsor di fillm AADC
2. Penonton akan ikut alur cerita dari film yang di dalamnya sudah disertakan iklan yang tidak terpisah dari cerita film. Hal tersebut akan meminimalisir penonton untuk merasa sedang di branding.

Dengan demikian, peneliti berpendapat bahwa narrative marketing maupun entertainment branding yang diangkat dalam penelitian ini dapat dimasukkan ke dalam kategori soft-selling karena upaya dari keduanya cara pemasaran tersebut yang mengedepankan nilai (value) yang terkandung dari sebuah produk dibandingkan mempromosikan produk tersebut secara gamblang untuk segera dibeli oleh masyarakat.

\section{SIMPULAN}

Terdapat beberapa alasan mengapa pihak brand mau menggunakan konsep dari filmmakers dengan pendekatan soft-selling. Selain pihak brand telah melihat portofolio dari filmmakers, filmmakers memperlakukan karya branded web series layaknya karya film pada umummnya. Karena kesuksesan dari serial web Sore, Tropicana melanjutkannya dengan serial web Janji. PihakToyota juga sejak awal melirik cara bercerita dari serial web Sore dan sejak awal pula telah menginginkan untuk dibuatkan branded web series yang tidak hardselling. Namun terdapat sebuah kesepakatan kunci yang harus disetujui oleh pihak brand jika menginginkan pihak Cerita Films sebagai production house proyek mereka. Pihak brand diminta untuk mempercayakan $100 \%$ proses kreatif kepada pihak production house.Selain itu, fimmakers dibukakan kebebasan sebesar mungkin dengan tetap mengemban tanggung jawab serta kedewasaan yang telah disepakati, yaitu mengutamakan visi dari market yang diinginkan pihak brand.

Strategi filmmakers dalam menyampaikan pesan dengan cara soft-selling terbagi menjadi beberapa bagian. Pada tahap development, Cerita Films memiliki konsep bank story dimana terdapat kumpulan-kumpulan cerita berbentuk sinopsis panjang yang nantinya kemudian dipilih kepada klien mana ceritacerita tersebut paling tepat untuk diproduksi 
lebih lanjut. Selain itu, setiap product placement yang terdapat dalam konten telah disesuaikan dengan dramaturgi adegan sehingga konsepnya menyatu dengan cerita. Pada tahap pra-produksi, proyek yang berlangsung harus diberikan atensi secara penuh dengan persiapan yang panjang. Saat tahap produksi, pihak agensi maupun brand tidak dapat melakukan intervensi apapun selain hal-hal fundamental yang berkaitan dengan framing produk. Selain itu, penting bagi filmmakers untuk membuat sebuah ekosistem yang sehat dalam bekerja.

Dengan makin meningkatnya kue iklan banyak produk di ranah digital, peluang branded web series di ranah digital dalam lima tahun kedepan diproyeksikan masih sangat cerah. Namun pesona channel komunikasi above the line masih tidak akan memudar karena keefektifannya dalam menebarkan exposure secara masif. Tujuan dari membuat branded web series dirasa masih berfokus pada pembentukan citra produk ataupun perusahaan dibandingkan upaya untuk melakukan konversi awareness menuju ke sales. Banyak konsumen yang tidak lagi memelihat sebuah produk secara fungsionalnya, namun lebih ke arah emosi yang ditanamkan dalam produk tersebut. Para produsen konten terus menerus berusaha mengembangkan proses story telling ke arah yang lebih personal dibandingkan berusaha untuk melihat target konsumen secara masif dan monoton, agar pesan yang tersampaikan terasa lebih intimate.

Terdapat beberapa saran akademis dan saran praktis yang dapat diberikan peneliti untuk penelitian selanjutnya. Saran akademis meliputi: Peneliti melihat bahwa ekosistem yang telah dibangun dalam pembuatan branded web series karya Yandy Laurens dengan production house Cerita Films sudah masuk dalam kategori ideal, maka ekosistem tersebut patut dipertahankan. Penelitian ini terbatas dengan fokus kepada branded web series karya Yandy Laurens kategori drama fiksi. Penelitian lebih lanjut dapat dilakukan dengan menggunakan fokus, metode serta paradigma yang berbeda.

Penelitian inijuga memberikan saran praktis kepada pihak-pihak lain yang menginginkan untuk membuat branded web series dengan pendekatan soft-selling layaknya karya dari Yandy Laurens berdasarkan dari hasil penelitian yang telah dilakukan. Tiap-tiap filmmakers agar dapat mendiskusikan dengan pihak brand ataupun agensi untuk dapat menemukan selling point dari tiap produk, mencatat hal-hal apa saja yang dapat mengungguli produk dari competitor lainnya, serta jelas menyasar market mana yang akan dituju. Selain itu, filmmakers diharapkan tidak menempatkan produk sebagai hero yang menuntuaskan semua permasalahan dari protagonis cerita. Produk harus diceritakan dengan natural dan tiap product placement yang ingin dibubuhkan agar diatur dalam rangkaian dramaturgi adegan sehingga masuk ke dalam cerita.

\section{DAFTAR PUSTAKA}

Bachri, B. S. (2010). Meyakinkan kualitas data melalui triangulasi pada penelitian kualitatif. Jurnal Teknologi Pendidikan, 10 (1), 46-62.

Binus. (2017). Customer path. Diakses dari https:// scdc.binus.ac.id/imcb/2017/10/customer-path$5 \mathrm{a} /$.

Digital 2019: Indonesia. (2019). Diakses dari https://datareportal.com/reports/digital-2019indonesia? $\mathrm{rq}=$ indonesia.

Doyle, C. (2019). AIDA dalam a dictionary of marketing. Diakses dari https:// oxfordreference.com/view/10.1093/oi/ authority.20110803095432783.

Dutta, N. (2019). How is branded content different from native advertising?. Diakses dari https:// vidooly.com/blog/difference-betweenbranded-content-and-native-advertising.

Ibrahim, I. S. (2011). Budaya populer sebagai kamunikasi; dinamika popscape dan mediascape di indonesia kontemporer. Yogyakarta: Jalasutra.

Kennedy, J. E. \& Soemanagara, R. D., (2006). Marketing communication - taktik dan strategi. Jakarta: Buana Ilmu Populer.

Kotler, P. \& Keller, K. L., (2012). Marketing management. Jakarta: Indeks Kelompok Gramedia.

Permana, R. S., Abdullah, A., Mahameruaji, J. N. (2019). Budaya menonton televisi di indonesia: dari terrestrial hingga digital. Pro TVF, 3 (1), 53-67.

Rulianto, A. (2018). Yandy laurens: semua seni ada disiplin ilmunya. Diakses dari: https:// jurnalruang.com/read/1520575744-yandylaurens-semua-seni-ada-disiplin-ilmunya. 
Ryte Wiki. (2019). AIDA. Diakses dari https:// en.ryte.com/wiki/AIDA.

Sabdarini, I. T. (2019). Opus creative economy outlook 2019. Diakses dari https://bekraf.go.id/ pustaka/page/89-opus-creative-economyoutlook-2019-indonesia-version.

Salim, A. (2006). Teori dan paradigma penelitian sosial. Yoyyakarta. Penerbit Tiara Wacana.

Savitry, Y. (2019). ATL \& BTL integration. Diakses dari https://www.youtube.com/. tch? $\mathrm{v}=\mathrm{cj} 49 \mathrm{EdLR}$ tyY\&list=PLkKNAUVeVU
qyQdFfjO9zejCVXC4wdYBw\&index $=24$.

Tampi, E. N. \& Pamungkas, I. N. (2018). Analisis customer path 5a pada sponsor film AADC 2 sebagai program entertainment branding. Pro TVF, 2 (1), 69-86.

Tulus, B. Y. (2019). Belanja iklan digital Indonesia capai rp 40 triliun di 2018. Diakses dari https:// merdeka.com/uang/belanja-iklan-digitalindonesia-capai-rp-40-triliun-di-2018.html.

Yin, R. K. (2014). Studi kasus: desain dan metode Jakarta: RajaGrafindo Persada. 